\title{
Effects of Modulation Index on Harmonics of SP-PWM Inverter Supplying Universal Motor
}

\author{
Asif A. Solangi \\ Mehran UET SZAB Campus, \\ Khairpur Mir's Sindh Pakistan
}

\author{
Mehr Gul \\ Balochistan University of \\ Information Technology, \\ Engineering and Management \\ Sciences, Balochistan Pakistan
}

\author{
Rameez Shaikh \\ Sukkur IBA University, Sindh \\ Pakistan
}

Farhana Umer

The Islamia University of

Bahawalpur, Punjab Pakistan

\author{
Noman Khan Pathan \\ Mehran UET SZAB Campus, \\ Khairpur Mir's Sindh Pakistan
}

\author{
Zeeshan Anjum Memon \\ Mehran UET SZAB Campus, \\ Khairpur Mir's Sindh Pakistan
}

\begin{abstract}
This manuscript presents the effects of changing modulation indices on current and voltage harmonics of universal motor when it is supplied by single phase PWM (SPPWM) inverter, the effect has been analyzed with simulation and experimental setup. For variable speed applications universal motor can be controlled either by phase angle control drive or by SP-PWM inverter drive. SP-PWM inverter-fed drive is common technique that is used to adjust the voltage applied to motor, so that variable speed can be obtained. With the application of SPPWM inverter-fed drive, harmonics are generated because of power electronic devices. According to the IEEE standard 519, the total harmonic distortion (THD) must be within 5\%. In this paper, the effect of modulation index (MI) is used to analyze THD content, and its variation alters the harmonic content. However, the effects are also analyzed through experimental setup in order to validate the system performance. In future work, keeping modulation index constant, different PWM strategies can be employed in order to decrease harmonics.
\end{abstract}

Keywords-Harmonics; modulation index; SP-PWM inverter; universal motor

\section{INTRODUCTION}

In recent years speed control of universal motor by using SP-PWM inverter fed drive is widely used because of its efficient control [1], [22]. In operation, universal motor is very similar to series dc motor, but unlike dc series it can be operated on ac voltage also. Universal motor is designed to operate on either dc or ac. Universal motor is different from dc series motor construction wise. Direction of torque is same for any current polarity as well as ac current. Universal motor have some good features due to its more power related to its size and weight. As compared to induction motor universal motor is popular because of its high speed ranging from (1500 to $2000 \mathrm{RPM})$. Universal motor is suitable for washing machines, drills and dust extractors. Universal motor have also some drawbacks because of sparking produced by commutator segments. And also lower life time and loud noise as compared to induction motor. Due to advancement in power electronics technology, power inverters are widely used in power systems, household appliances, transportation, specifically in variable frequency drives [2]. Speed of universal motor can be controlled by using two types of controllers i.e. phase angle control (using TRIAC or Thyristor) or by with PWM converters (Using IGBT) [3]. Using such type of convertors speed of universal motor can be controlled by adjusting output voltage of converter. As universal motor is widely used in home appliances so the controllers are designed to operate on ac voltage [4]. SP-PWM inverter -fed drive is common technique that is used to adjust the voltage applied to motor [5]. With PWM inverter-fed drive harmonics are generated because of application of power electronic devices used in the circuitry. The harmonics produced must be within allowable limit of $5 \%$ as recommended by IEEE standard 519, so that other loads may not be affected by harmonics produced. Different methods are proposed to decrease THD content generated by SP-PWM inverter-fed drive supplying universal motor. Voltage source inverters are implied in Sinusoidal pulse width modulation techniques, VSI are remained area of interest for researchers. In SP-PWM inverter -fed drive, some parameters effect the production of harmonic content, out of these parameters modulation index should be changed to control amplitude and speed. So variation of modulation index is analyzed [6]. With the application of single phase PWM inverter-fed drive the iron loss in electric sheets of stator and rotor can be reduced significantly [5]. The increased awareness of harmonics in recent years is the result of concerns that harmonic distortion levels are increasing on many electrical power systems [7], however, this is the hot research direction now-a-days, the emphasis is on the cost effective exploitation regarding power quality and reliability [8]. Today's one of the most serious issue due to which industrial consumers are suffering financial losses enforced by utility regulations is power quality. Out of several PQ disturbances THD is most common type of disturbance, thus it's necessary to analyze THD content due to usage of power electronic components used in household appliances to guarantee the more pure form of power to customers [9]. Due to these harmonics, problems are created which include interference with communication lines, degradation of insulation levels of equipments, heating of 
winding, excessive currents, increased power losses which ultimately reduce life of equipment. Harmonics affect power quality and increase system losses up to $20 \%$ out of which $27 \%$ may be attributed to harmonics [10-11]. Recent studies reveal that the additional power losses in distribution networks may be in range of $4-8.5 \%$ for various harmonic levels [12]. Power electronic converters are used in VFDs and ultimately causes elevated harmonics into the system. Design engineers and semiconductors suppliers are interested in energy efficient and low cost variable frequency drives. PWM based variable switching frequency technique is proposed to reduce total harmonic distortions [13], in addition, the use of very high range of switching frequency is not suitable for semiconductor switches of real grid-connected inverters [14]. As per the IEEE standards 519, current and voltage total harmonic distortion must be restricted lower than 5\%. PWM controllers operating at elevated index of modulation causes decline in THD. In universal motor, steady speed control system is supplied by pulse width modulation controlled through ac chopper, additionally providing enhanced range of speed and ultimately reacting even healthier under abrupt alterations in load [15]. In this research work development of simulation models of universal motor and PWM controlled single phase inverter-fed drive is presented by using Matlab/Simulink/Simscape software. A simulation model is developed for harmonic analysis of universal motor when it's fed by SP-PWM controlled single phase inverter-drive. Same work is done experimentally, by using a reference variable generator, PWM controller, single phase IGBT driver set. Harmonic analysis is done with different modulation indices. Experimental and simulation results are observed nearly equal. Harmonic contents are lower at higher modulation indices. Section III contains equations related to voltage and current for universal motor. Different speed control techniques are also discussed in this section. Simulation model for Universal motor supplied by single phase inverter is described in Section IV. Detail of experimental setup for harmonic analysis of the system is also given in this section. Results are compared and discussed. Finally paper is concluded in Section V.

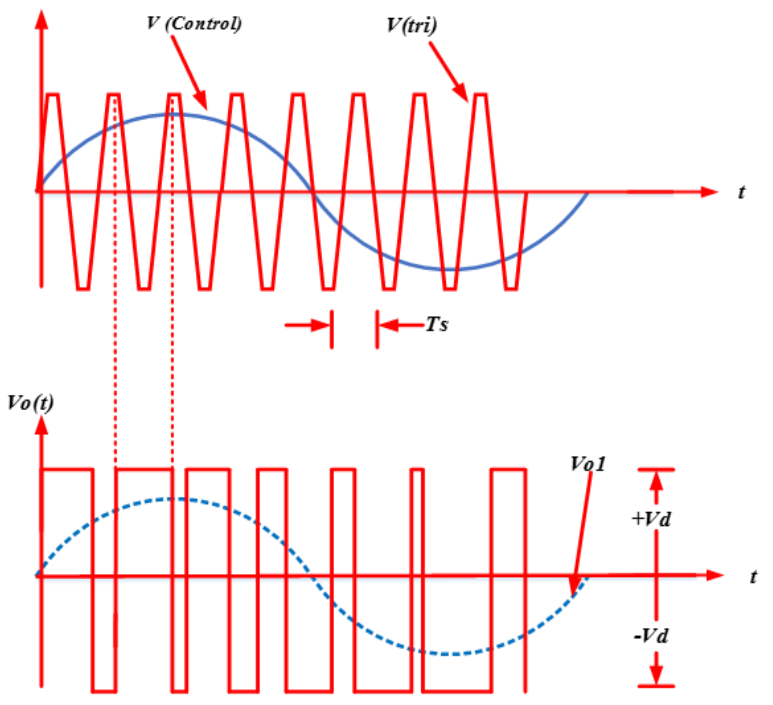

Fig. 1. Sinusoidal pulse width modulation.

\section{Sinusoidal Pulse Width Modulation}

Many industrial applications use variable speed drives, and PWM is mostly common technique used in these variable speed drives. Among different PWM techniques sinusoidal pulse width modulation is widely used. In sinusoidal pulse width modulation width of gating pulse is changed in accordance with the width of reference signal. The control signals are generated by comparing sinusoidal wave with triangular or squire wave as shown in Fig. 1, the frequency of reference signal determines the inverter output frequency, in result it controls the modulation index whereas number of pulses per half cycle depends upon the frequency of carrier signal. DC input voltage is fed to SP-PWM for producing sinusoidal wave at prescribed frequency. There are two SPPWM techniques for $\mathrm{H}$-bridge inverter which are unipolar and bipolar switching [16] SPWM technique has reduced power loss, because of its switching devices remain almost off (Low current means low power) and remain hardly on (Low voltage, low power) PWM signals can easily be generated by using modern microcontrollers [17].

\section{SPEED CONTROL OF UNIVERSAL MOTOR}

Universal motor is mostly supplied by single phase ac voltages [18], [21]. Fig. 2 shows schematic diagram for universal motor. System of equations for field voltages and voltage of armature are shown in (1).

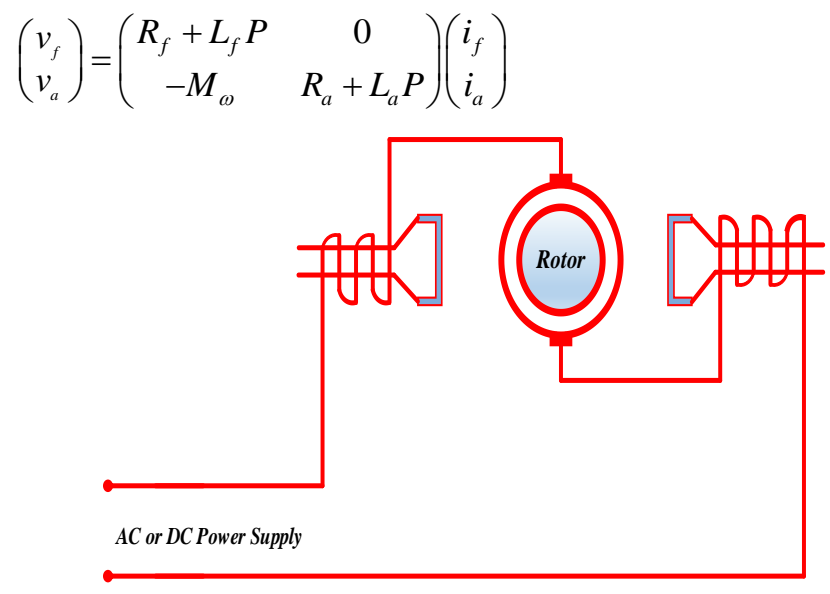

Fig. 2. Schematic diagram of universal motor.

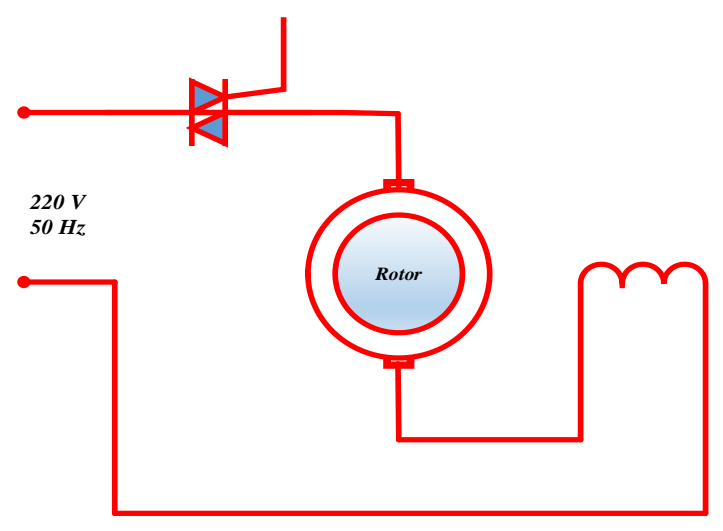

Fig. 3. Speed control of motor using TRIAC. 


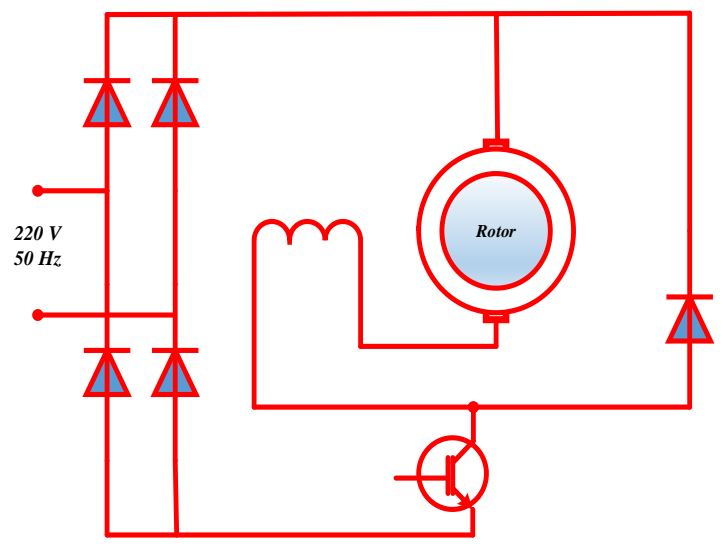

Fig. 4. Speed control of motor using chopper.

Where, the field and armature currents are related by (2).

$$
\left(\begin{array}{l}
i_{f} \\
i_{a}
\end{array}\right)=\left(\begin{array}{l}
1 \\
1
\end{array}\right)[i(t)]
$$

The voltage across the winding are related by

$$
v(t)=\left(\begin{array}{ll}
1 & 1
\end{array}\right)\left(\begin{array}{l}
v_{f} \\
v_{a}
\end{array}\right)
$$

By using (2) and (3), the voltage equation can be rewritten as

$$
v(t)=\left(\begin{array}{lll}
R & L P & M_{\omega}
\end{array}\right) i(t)
$$

Where

$$
\begin{aligned}
& R=R_{a}+R_{f} \\
& L=L_{a}+L_{f}
\end{aligned}
$$

Speed of universal motor is mostly controlled by using ac chopper and phase angle control method. TRIAC is used in phase angle control technique to control the amount of voltage supplied to the universal motor as shown in Fig. 3. In the chopper control application, voltage applied to the motor is adjusted by using PWM technique. Amount of voltage supplied to motor is changed by variations in duty cycle of PWM signal [19]. Carrier frequency also affects the THD [20]. AC power chopper needed one more stage and it consists of power switch rectifier and fast switching power diode. Simplified chopper control technique using IGBT is shown in Fig. 4. Industrial applications requiring superior performance are using PWM based VFDs. Improvement in power electronics control circuits is caused by recent developments in power semiconductor industry. Hence, different circuit configurations, namely, PWM inverters have become popular. A number of PWM schemes are used to obtain variable voltage and frequency supply. The most widely used PWM scheme for voltage source inverters is sinusoidal PWM [16]. In accordance with the sine function, the inverter output voltage and frequency can be controlled by using SPWM technique. In this scheme the width of each pulse is varied in proportion to the amplitude of a sine wave evaluated at the center of same pulse. The gating signals are generated by comparing a sinusoidal reference signal with a triangular carrier wave of frequency $f_{c}$. The frequency of reference signal $f_{r}$ determines the inverter output frequency $f_{o}$; and its peak amplitude $A_{r}$ controls the modulation index $M$, and then in turn the RMS. The output voltage $V_{o}$ if $\delta m$ is the width of $m$ the pulse the output RMS voltage can be determined by

$$
V_{o}=\left(\sum_{m=1}^{2 p} \frac{\delta m}{\pi}\right)
$$

\section{SIMULATION AND EXPERIMENTAL DETAILS}

Fig. 5 shows the simulation model of single phase pulse width modulator inverter fed supplying universal motor. A physical system in Simulink environment is introduced by the model consisting of Simscape. Simscape is used to make control block diagrams of universal motor, while single phase pulse width modulator is built in Simulink. Pulse width modulator generator helps in altering index of modulation and switching frequency. The fast fourier transform is presented as a tool for analysis for various indices of modulation and frequency of switching. Ideal block of rotational motion sensor represents ideal mechanical rotational sensor. Ideal block of rotational motion sensor helps in conversion of variable (across) between 2 nodes of mechanical rotation into angular velocity in proportion to signal of control. The block of ideal torque source denotes ideal mechanical source. The simulation parameters to model universal motor are $J=2 \mathrm{e}-4$; $B=1 \mathrm{e}-6, R_{a}+R s=90 \Omega ; L_{a}+L_{s}=181 \mathrm{mH}$

Experimental setup of harmonic analysis of universal motor when it's fed by SPWM controlled single phase inverter-fed drive is shown in Fig. 6. Starting from the left dc Power supply module that is required to provide dc power supply is to reference variable generator for single phase PWM controller. The output voltage of reference variable generator is used as command input voltage of the SP-PWM controller. SP-PWM controller module is used to generate gating signals of IGBT driver set module. IGBT driver set produces dc at its output terminals from dc voltage at its input. Frequency of output voltage depends upon the frequency of command voltage and the peak value of reference signal controls the average output voltage. Power quality analyzer is used to measure THD for current and voltages, it also display harmonic orders with respect to fundamental frequency. Harmonic spectrum response is taken at different M.I. Fig. 7 shows FFT analysis for current of system under discussion for carrier frequencies of $1 \mathrm{kHz}$ with modulation index of 0.6 . It shows a $\mathrm{THD}_{i}$ of $50.10 \%$. Both even and odd harmonics are present in harmonic spectrum. As shown in Fig. 8 waveform is not pure sinusoidal because it's obtained at lower modulation index.

Fig. 9 shows experimental results for harmonic spectrum of system with $1 \mathrm{kHz}$ carrier frequency with modulation index of 0.6. It shows $\mathrm{THD}_{i}$ of $56.1 \%$ which is nearly equal to simulation results, quite acceptable considering system parameter variations with temperature, parasitic effects in motor as well as single phase PWM inverter circuit, wiring and supply voltage. 




Fig. 5. Matlab based simulation model of universal motor fed by single phase PWM inverter.



Fig. 6. Experimental setup for universal motor fed by SP-PWM inverter.

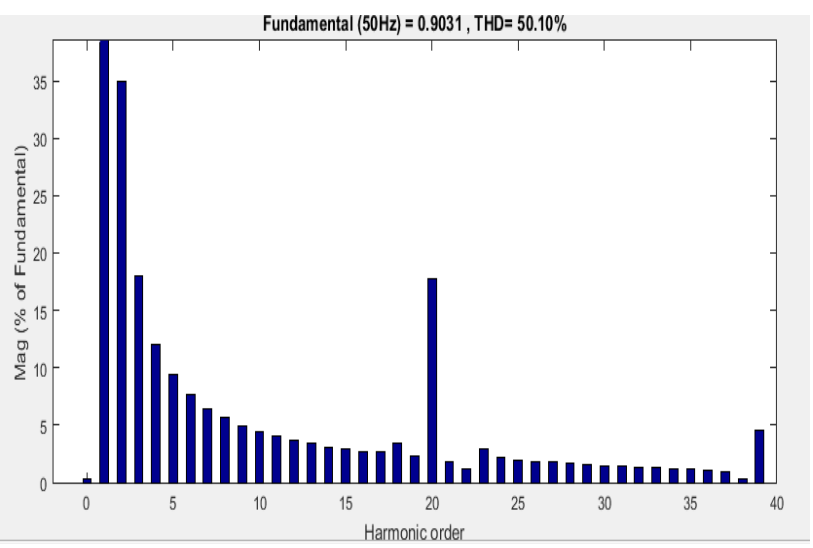

Fig. 7. Simulation based current harmonic spectrum response at $1 \mathrm{KHz}$ frequency with M.I of 0.6.

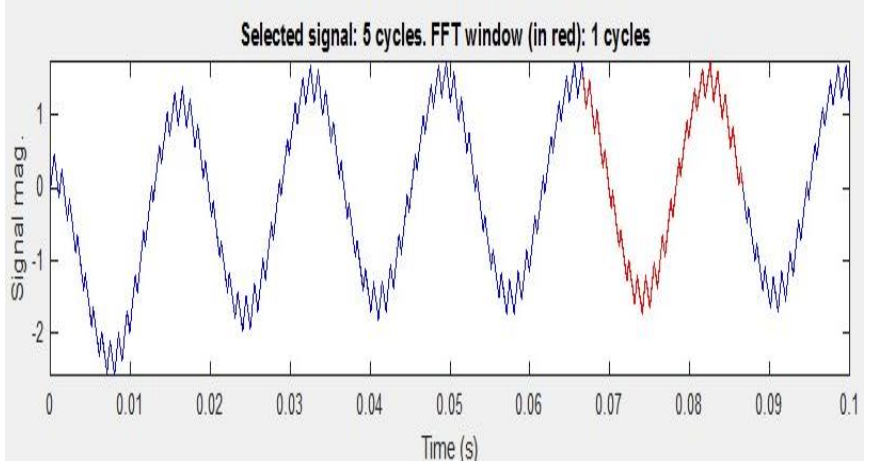

Fig. 8. Output current waveform using simulation at modulation index of 0.6 with $1 \mathrm{kHz}$ carrier frequency.

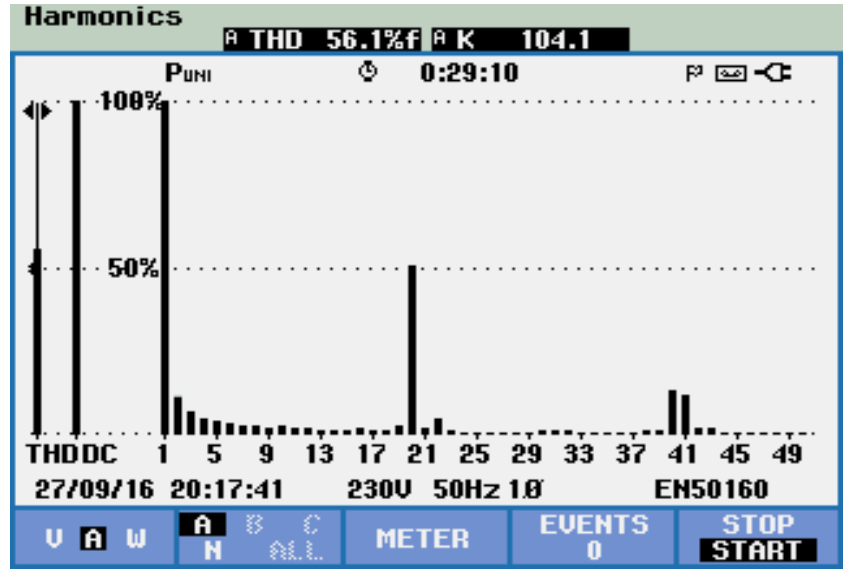

Fig. 9. Experimental based current harmonic spectrum response at $1 \mathrm{Khz}$ frequency with M.I of 0.6 . 




Fig. 10. Output current waveform using experimental setup at modulation index of 0.6 with $1 \mathrm{KHz}$ carrier frequency.

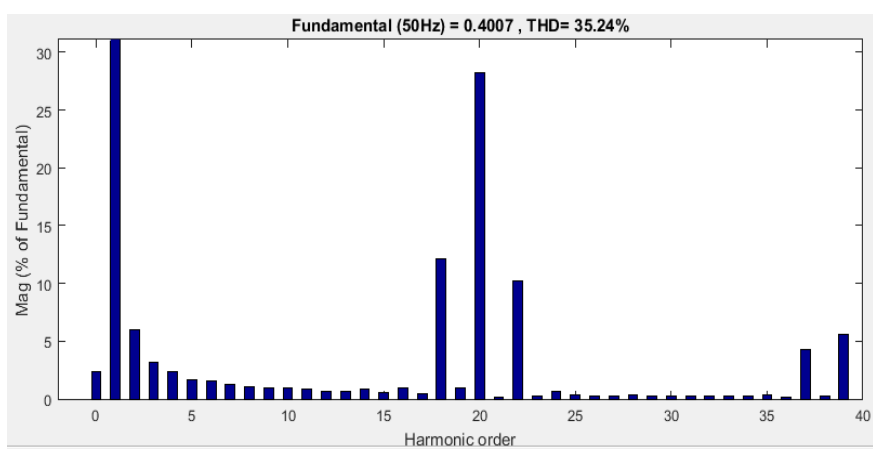

Fig. 11. Simulation based current harmonic spectrum response at $1 \mathrm{kHz}$ frequency with M.I of 0.9.



Fig. 12. Experimental based current harmonic spectrum response at $1 \mathrm{kHz}$ frequency with M.I of 0.9 .

Fig. 10 shows output current wave form with experimental setup at modulation index of 0.6 with distorted waveform by further increasing modulation index at value of 0.9 , and simulation results for current harmonics are obtained, Fig. 11 and 12 , respectively show simulation and experimental harmonic analysis for current of system under discussion with modulation index of 0.9 and it is observed that harmonics are reduced considerably with increasing modulation index when its compared with FFT analysis of current at modulation index of 0.6. Increased modulation index i.e. 0.9 affects the output waveform current; it is shown in Fig. 13, that simulation based output current waveform is more sinusoidal then current waveform observed at modulation index of 0.6. Experimental output waveform form for current is shown in Fig. 14.
Fig. 16 and 17, respectively show simulation and experimental harmonic analysis for current of system under discussion with modulation index of 1 .



Fig. 13. Output current waveform using simulation at modulation index of 0.9 with $1 \mathrm{kHz}$ carrier frequency.

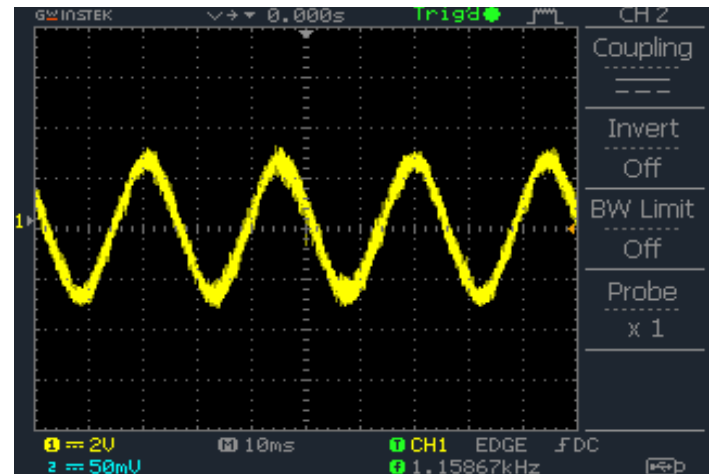

Fig. 14. Output current waveform using experimental setup at modulation index of 0.9 with $1 \mathrm{kHz}$ carrier frequency.

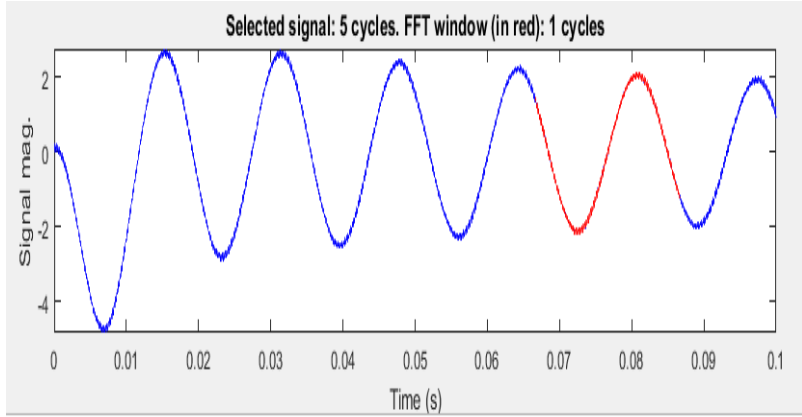

Fig. 15. Simulation based current harmonic spectrum response at $1 \mathrm{kHz}$ frequency with M.I of 1 .

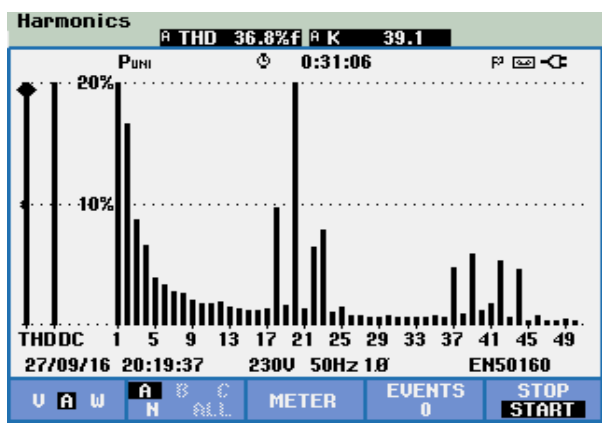

Fig. 16. Experimental based current harmonic spectrum response at $1 \mathrm{kHz}$ frequency with M.I of 1 . 


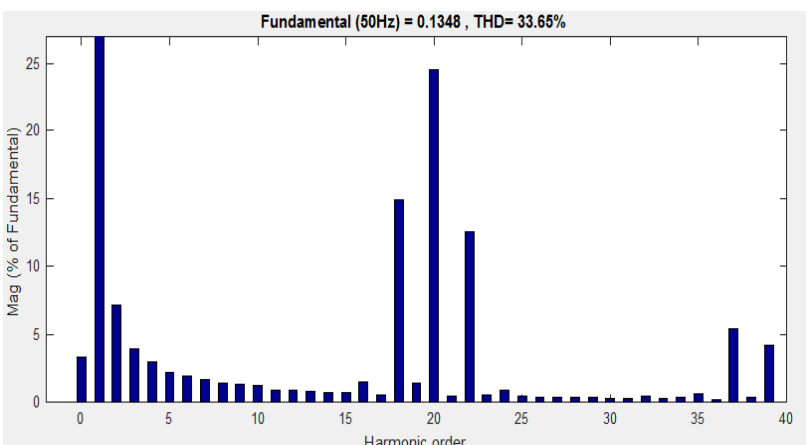

Fig. 17. Output current waveform using simulation at modulation index of 1 with $1 \mathrm{kHz}$ carrier frequency.


Fig. 18. Simulation based output current wave form at three different modulation indices.



Fig. 19. $\mathrm{THD}_{i}$ at different modulation indices at constant carrier frequency of $1 \mathrm{kHz}$.

At modulation index of 1 , output current waveform is pure sinusoidal as shown in Fig. 15. Comparison of output current waveforms with different modulation indices is shown in Fig. 18 and it's observed that when M.I is fixed at 1, then output current waveform is more sinusoidal. Results of $\mathrm{THD}_{i}$ for different modulation indices are shown in. Carrier frequency is fixed at $1 \mathrm{KHz}$. It is clear that increasing modulation index current harmonics are decreasing; it's also observed that best output signal is produced by increasing the modulation index graphically it's shown in Fig. 19. Current harmonics will cause harmonics in voltage. These voltage harmonics will affect operation of other appliances connected to the supply network. THDv for three modulation indices were also observed using simulation and experimental arrangements. Fig. 20 shows FFT spectrum of voltage harmonics at modulation index of 0.6 with keeping the carrier frequency constant at $1 \mathrm{kHz}$ and modulation index of 0.6 , experimental results of voltage harmonics are shown in Fig. 21.



Fig. 20. Simulation based voltage harmonic spectrum response at $1 \mathrm{kHz}$ frequency with M.I of 0.6 .

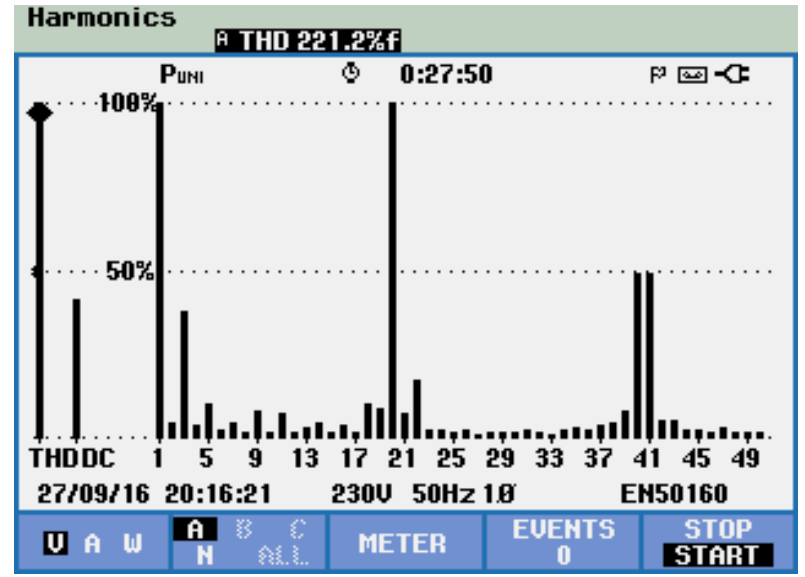

Fig. 21. Experimental based voltage harmonic spectrum response at $1 \mathrm{kHz}$ carrier frequency with M.I of 0.6.

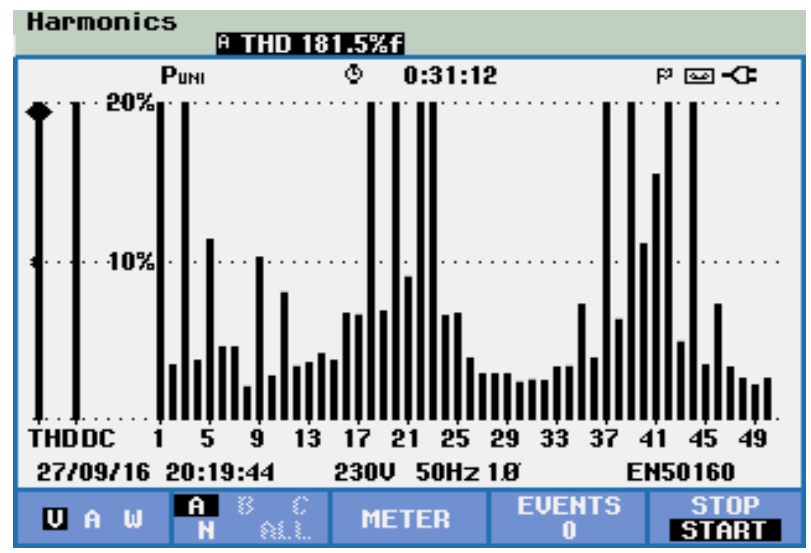

Fig. 22. Experimental based voltage harmonic spectrum response at $1 \mathrm{kHz}$ frequency with M.I of 0.9 . 


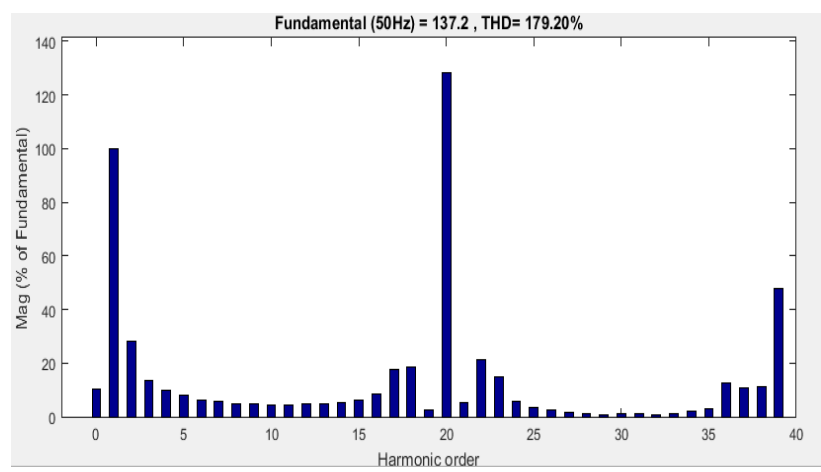

Fig. 23. Simulation based voltage harmonic spectrum response at $1 \mathrm{kHz}$ frequency with M.I of 0.9.

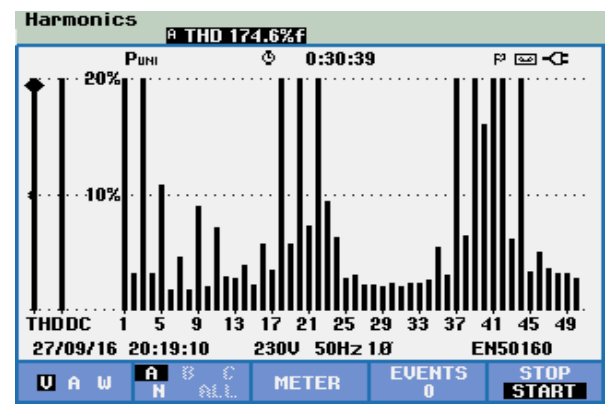

Fig. 24. Experimental based voltage harmonic spectrum of PWM based inverter fed universal motor with $1 \mathrm{kHz}$ carrier frequency with modulation index of 1 .

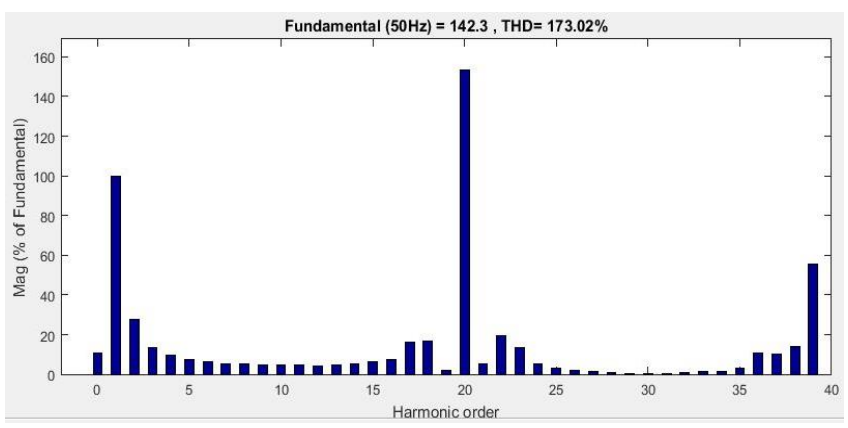

Fig. 25. Simulation based voltage harmonic spectrum response at $1 \mathrm{kHz}$ frequency with M.I of 1 .

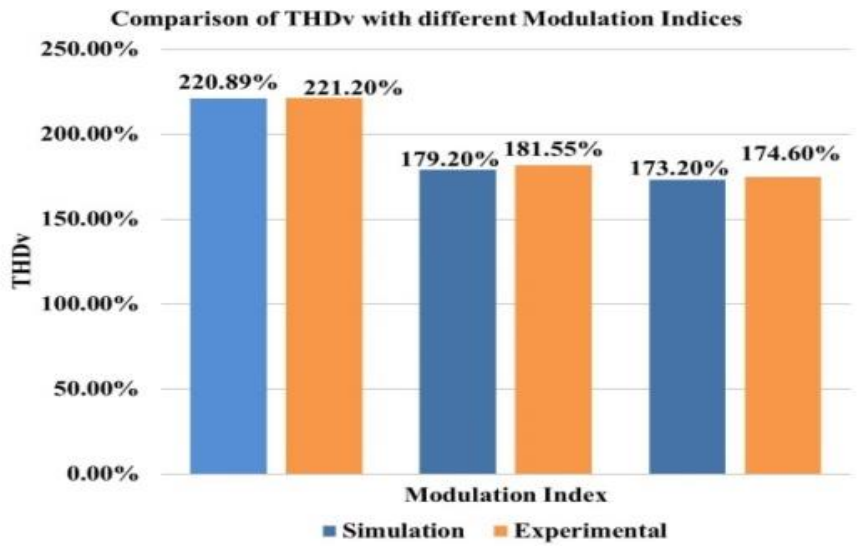

Fig. 26. $\mathrm{THD}_{v}$ at different modulation indices at constant carrier frequency of $1 \mathrm{kHz}$.
With further increasing modulation index it can be observed that harmonic contents are reducing significantly Fig. 22 and 23 shows the harmonic content using simulation and experimental setup at modulation index of 0.9 but with same carrier frequency with further increase of modulation index, the voltage harmonic content are reducing which can be observed from Fig. 24 and 25 for both simulation and experimental setup at modulation index of 1 . Comparison of THDv for different modulation indices are graphically shown in Fig. 26.

\section{CONCLUSION}

Most of household appliances use universal motor in their operation and some of applications in industries. Its output torque is controlled through variations in supply voltage. When universal motor is operated for variable speed or high torque applications by incorporating power electronic converters in result harmonics are generated. Nature of harmonics generated imparts adverse effects on performance of universal motor and also other connected equipment. In this research work, harmonic analysis of single phase pulse width modulator inverter with various indices of modulation supplying universal motor is the focus of study. However at very higher switching frequencies losses will be more, this limits the work. A single phase pulse width modulation inverter supplying universal motor is modeled in MATLAB. In order to validate simulated results experimental arrangement is also established. Results show that content of voltage and current harmonics are more than standard limit of $5 \%$ as set by IEEE Standard 519. It is also concluded that THD decreases with increasing modulation index. In future work, keeping modulation index constant, different PWM strategies can be employed in order to decrease harmonics.

\section{ACKNOWLEDGMENTS}

This work is highly acknowledged by Mehran University of Engineering \& Technology SZAB Campus, Khairpur Mirs for their support regarding reserch conducted at Labaorory, and we would like to say thanks to Engr. Dr. Mazhar Hussain Baloch Assistant Professor (Electrical Engineering), Mehran University of Engineering \& Technology SZAB Campus, Khairpur Mirs for their support regarding review our paper and some suitable guidence about paper publication.

\section{REFERENCES}

[1] Tahir, S., Wang, J., Baloch, M. H., \& Kaloi, G. S. (2018). "Digital control techniques based on voltage source inverters in renewable energy applications" A Review on Electronics, 7(2), 18.

[2] J. Song, X. Zhang, L. Zheng, Y. Gao, and Y. Song (2015) "Simulation and experiment of three-phase voltage SPWM inverter" Proceedings of IEEE 10th Conference on Industrial Electronics and Applications" pp. 1324-1329.

[3] Y. S. Lai (2003) "Machine modeling and universal controller for vectorcontrolled induction motor drives" IEEE Trans. on Energy Conversion, vol. 18, no. 1, pp. 23-32

[4] Kaňuch, J., \& Višnyi, P. (2009) "DC drive for universal motor" Maszyny elektryczne: Zeszyty problemowe pp. 7-11.

[5] Bodur, H., A.F. Bakan, and M.H. Sarul, (2000) "Universal motor speed control with current controlled PWM AC chopper by using a microcontroller" Proceedings of IEEE International Conference on Industrial Technology, Goa, India. pp. 394-398.

[6] Hassan Feshki, F., \& Sarabadani, H. (2011). "Modulation index effect on the 5-level SHE-PWM voltage source inverter" Engineering. 
[7] Kumar, M., Memon, Z. A., Uqaili, M. A., \& Baloch, M. H. (2018). "An Overview of Uninterruptible Power Supply System with Total Harmonic Analysis \& Mitigation: An Experimental Investigation for Renewable Energy Applications" IJCSNS, 18(6), 25.

[8] Baloch, M. H., Wattoo, W. A., Kumar, D., Kaloi, G. S., Memon, A. A., \& Tahir, S. (2017). "Active and Reactive Power Control of a Variable Speed Wind Energy Conversion System based on Cage Generator" International Journal of Advanced Computer Science and Applications, Vol 8(9), pp.197-202.

[9] Halepoto, I.A, F.R. Abro, A.R. Chachar, Adeena, (2016) "Power Quality Assessment of Compact Fluorescent Lamps," Sindh University Research Journal-SURJ (Science Series), pp. 407-412

[10] Kharlov, N.N., Borovikov, V.S., Ushakov, V.Y., Tarasov, E.V. and Bulyga, L.L (2016) "Calculation of steady non-sinusoidal modes and electric power losses in complex electrical networks" International Conference on Power Electronics and Motion Control (PEMC) pp. 336341

[11] Neagu, B. C., Georgescu, G., \& Ivanov, O. (2016). "The impact of harmonic current flow on additional power losses in low voltage distribution networks" (2016) International Conference and Exposition on Electrical and Power Engineering (EPE) pp. 719-722

[12] Kalair, A., Abas, N., Kalair, A.R., Saleem, Z. and Khan, N (2017) "Review of harmonic analysis, modeling and mitigation techniques" Renewable and Sustainable Energy Reviews, pp.1152-1187

[13] Mao Xiaolin, Ayyanar Rajapandian, Krishnamurthy Harish K. (2009) "Optimal variable switching frequency scheme for reducing switching loss in single-phase inverters based on time-domain ripple analysis" IEEE Trans Power Electrical pp. 991-1001

[14] Tran, Quang-Tho, Anh Viet Truong, and Phuong Minh Le (2016) "Reduction of harmonics in grid-connected inverters using variable switching frequency." International Journal of Electrical Power \& Energy Systems pp.242-251.
[15] Wang, R.H., and R, T.Walter, (2000) "Modeling of universal motor performance and brush commutation using finite element computed inductance and resistance matrices," IEEE Transactions on Energy Conversion, pp. 257-263.

[16] Aboadla E.H., S. Khan, M.H. Habaebi, T. Gunawan, B.A. Hamidah, and M.B. Yaacob (2016) "Effect of modulation index of pulse width modulation inverter on Total Harmonic Distortion for Sinusoidal," In IEEE International Conference on Intelligent Systems Engineering (ICISE), Islamabad, Pakistan, pp. 192-196.

[17] Namboodiri, A., \& Wani, H. S. (2014). "Unipolar and bipolar PWM inverter" International Journal for Innovative Research in Science \& Technology, pp. 237-243.

[18] Mirafzal, B., G.L. Skibinski, R.M. Tallam, D.W. Schlegel, and R.A. Lukaszewski, (2007) "Universal induction motor model with low-tohigh frequency-response characteristics," IEEE Transactions on Industry Applications, pp. 1233-1246

[19] Barge, S.A., and D.R. Jagtap, (2013)“Harmonic Analysis of Sinusoidal Pulse Width Modulation," International Journal of Advanced Electrical and Electronics Engineering, pp. 13-16.

[20] Solangi, A., Sahito, A., Soomro, S., Khatri, S., \& Memon, M. (2016). "Harmonic Analysis of Universal Motor Supplied by Single Phase PWM Inverter-Fed Drive". Sindh University Research Journal-SURJ (Science Series), Vol. 48 (4) pp.769-774.

[21] Memon, A. A., Shah, S. A. A., Shah, W., Baloch, M. H., Kaloi, G. S., \& Mirjat, N. H. (2018). "A Flexible Mathematical Model for Dissimilar Operating Modes of a Switched Reluctance Machine". IEEE Access, 6, 9643-9649.

[22] Tahir, S., Wang, J., Kaloi, G. S., \& Baloch, M. H. (2017). "Robust digital deadbeat control design technique for 3 phase VSI with disturbance observer". IEICE Electronics Express, 14(13), 2017035120170351. 